\title{
RECENT ADVANCES IN POLIOMYELITIS \\ The Epidemiology of Poliomyelitis
}

\author{
By J. H. S. GeaR, B.Sc., D.P.H., D.T.M. and H. \\ Rickettsial and Virus Diseases Laboratory, South African Institute of Medical Research, Fohannesburg
}

Poliomyelitis is an age old disease, but it was only clearly recognized as a clinical entity in the first half of the last century. Until the middle of last century it usually occurred in endemic sporadic form. Small outbreaks were recorded in St. Helena, 1834, in England, 1834, and in the United States, 1843. The first large epidemic occurred in Scandinavia in 1868 . In the 1890 's large epidemics began to appear in the Northern United States. Since then, epidemics have recurred at frequent intervals in these countries. More recently extensive epidemics have occurred in Australia and New Zealand. It is of considerable significance that the countries most severely affected have the highest standards of living and of hygiene and sanitation. As other countries have attained comparable standards, they in turn have suffered extensive epidemics.

\section{Geographical, Racial and Age Distribution \\ Prior to the recent war, poliomyelitis was thought to be a rare disease in tropical and sub- tropical countries. However, the incidence of paralytic cases does not necessarily reflect the incidence of infection. Indeed, it is now clear from observations made during the recent war that poliomyelitis is a common infection in the tropics.}

In the Middle East, Paul, Havens and van Rooyen (1944) noted that the incidence in American soldiers was ten times what it was in American soldiers in the United States. Cases occurred among local children in Egypt but severe paralytic infections, resembling those observed in newly-arrived Australian, New Zealand, American and European soldiers, could not be traced in the adult Egyptian civilians or soldiers. In Malta, the epidemic beginning late in 1942 affected the Maltese children under five years old most severely. Of 6I persons over the age of 20 affected only four were Maltese, the remainder being servicemen from the United Kingdom (Seddon, 1943). In India McAlpine (1945) noted the striking fact that the disease was five times more common in British officers than in other ranks.

In Japan Paul (1947), noted that endemic poliomyelitis was common, but that large epidemics did not seem to have been described there prior to 1938 . He also notes that in Europe and the United States during the late nineteenth century poliomyelitis was regarded as being rather rare after the age of 6 , but that during the past generation the age group attacked tends to be older than it was before. He suggests the possibility that a large amount of virus may persist in endemic areas such as Japan, and as a result the local population is continually becoming immunized very extensively. Under these circumstances only small children are left as the most susceptible group and are thus in a position to contract the disease.

In the South African epidemics of 1944-1945, it was noted (Gear, 1946) that the Bantu were less liable to paralytic poliomyelitis than Europeans. This difference in incidence seemed to be of considerable epidemiological significance. It was suggested that there may be inherent physiological differences in the susceptibility of the two races. Such variation has been noted in the relative susceptibilities of the Negro and of the European to malaria induced for therapeutic purposes. Diet may be concerned. It is known that diet influences the susceptibility of experimental animals to poliomyelitis. Thus mice fed on a diet deficient in thiamin are less susceptible to infection with the Lansing strain of virus than are normal mice. It may well be that the inadequate staple maize diet of the African națive accounts for his relative resistance to poliomyelitis. However, the most likely explanation appears to be that, in their relatively insanitary surroundings, people living under primitive conditions are regularly exposed to infection with endemic strains of the virus of poliomyelitis and so acquire an immunity not shared to the same degree by the more hygienic European. It thus is to be expected that, in epidemics, the latter will suffer more severely in all age groups except possibly in the youngest.

It has not yet been shown that endemic strains of poliomyelitis are more widespread amongst primitive people than amongst those with higher standards of living. There is evidence of this in the serological immunity that has been demon- 
strated by a mouse protection test, using the mouse-adapted Lansing strain of poliomyelitis to detect the presence or absence of antibodies in the serum of individuals. Surveys-using this mouse protection test-have revealed that immunity to the Lansing strain is low in infants, but with increasing age an increasing proportion of individuals show protection, until the majority of adults are immune. It has also been shown in countries with a mixed population, that in all age groups except the youngest the percentage of immunes is higher in the indigenous natives than in the European. It seems then that either the native reacts earlier to the same exposure of virus or, alternatively and more likely, that he is exposed earlier and more regularly to the infection. It is also evident from the surveys that poliomyelitis is indeed a world-wide disease, but that infection is probably more widespread in the relatively backward countries in the tropics and subtropics than elsewhere.

Since the end of the war serious epidemics have occurred in many countries. In some, epidemics were experienced for the first time. There is reason to believe that some of these epidemics followed the introduction of invasive strains of virus by servicemen and others returning from the Middle East and other theatres of war. Following the outbreaks in the Middle East in 1941, Malta was affected in 1942, South Africa in 1944, Mauritius and St. Helena in 1945, Northern Rhodesia in 1946, France in 1946, and Germany in 1947. Great Britain suffered her first extensive epidemic in 1947 .

\section{Seasonal Distribution}

In England the summer of 1947 was unusually early, warm and prolonged. It may be that there was a causal relationship between the warm weather and the prevalence of poliomyelitis. Indeed, it has often been suggested that epidemics of poliomyelitis can be correlated with rainfall and temperature, but no definite conclusion can yet be drawn as to which meteorological factors are concerned and how they act. There is no doubt however that in the temperate zone, although winter outbreaks have been described (Leake, 1947, Ward and Sabin, 1944), poliomyelitis is essentially a disease of the warm weather months. In the United States cases first occur in the south, then with the summer, poliomyelitis advances northwards to involve the Northern States, where it almost always reaches its peak incidence at the end of August or in the beginning of September. Several hypotheses have been advanced to explain his peculiar seasonal prevalence.

It is argued by Aycock (1948) that most infective diseases have a characteristic seasonal pattern, and he suggests that seasonal physiological changes in the host are responsible for increased susceptibility to poliomyelitis during the warm weather. It has been suggested that loss of chloride in sweating may increase the liability to infection with the virus (Rinehart, 1944).

The peculiar summer prevalence has led other investigators to suspect environmental factors in the spread of poliomyelitis. Before discussing these it will be appropriate to describe what is known of the virus responsible for this disease.

\section{The Virus}

Obviously it is essential to our understanding of the epidemiology of poliomyelitis that the number of strains of virus should be accurately known. Burnet and Keogh (1938) first suggested the existence of more than one. type of poliomyelitis virus when they showed that a strain isolated in the Victoria epidemic of 1937 was immunologically distinct from the Rockefeller Institute strain. Hitherto further investigation has been delayed by lack of a sufficient number of monkeys for the necessary tests. Now a beginning has been made on the study. Of about ten strains isolated in different epidemics in different years and in different parts of the United States, Morgan (1948) by her technique of intramuscular vaccination followed by intracerebral challenge has shown that they fall into two or three groups only. One of these is the Lansing type. The original Lansing strain was isolated from a fatal case of infantile paralysis occurring near Lansing in Michigan. Armstrong passaged this strain from monkeys to cotton rats, then to white mice. It has now been passaged many times in a large number of laboratories. Except for one relatively avirulent variant produced by Theiler, it is still highly virulent for monkeys when inoculated intracerebrally.

All the human strains of poliomyelitis, such as YSK and M.E.F.I., which it has been possible to transmit to rodents, have been found to be of the Lansing type. Although as already noted immunity to the Lansing virus is widespread, it seems that this type of virus is not often responsible for epidemics.

So far it has not been possible to transmit the non-Lansing type human poliomyelitis virus to any animals except primates. It has not yet been determined clearly how many different strains of virus are included in the non-Lansing group, but of those tested all fall into one, or at most, two. types (Morgan 1948).

At the recent International Poliomyelitis Conference in New York, it was agreed that the term poliomyelitis virus should be restricted to those viruses conforming to the original description of 
this agent. It is identified by the characteristic experimental disease in the monkey, by the character and distribution of the histological lesions in the spinal cord and brain of infected primates, by its host range, and by its immunological properties. These poliomyelitis viruses can be classified into two groups :

(a) Lansing type virus transmissible to monkeys and also to certain rodents including cotton rats and white mice.

(b) Non-Lansing type viruses transmissible to primates but not to any other experimental animal.

It was agreed that Theiler's virus, which causes a disease in mice clinically and pathologically similar to human poliomyelitis, should be known by the name he originally proposed, namely the virus of spontaneous mouse encephalomyelitis.

It was also agreed that the MM virus and the murine SK virus should not be included in the poliomyelitis virus group as their origin is in doubt.

The MM strain has been used for work on many aspects of virus. Unlike the true human poliomyelitis viruses, it has been cultured in fertile eggs (Enright \& Schultz, 1947). It has been isolated in highly purified form (Gollan, 1948). Vaccines have been prepared (Gard, 1947) and it has been used for chemotherapeutic experiments to test a large number of drugs (Bieter, 1948). While all this work is of great value in the field of general virus research, it cannot be applied to the virus of poliomyelitis.

Recently it has been shown that the MM virus and the virus of encephalomyocarditis isolated from a champanzee in Florida are immunologically similar (Warren, 1948), and that both are immunologically related to the Mengo virus recently described by Dick et al. (1948). The Mengo virus was isolated from a naturally paralysed monkey, from mosquitoes, and from a mongoose caught in the compound of the Yellow Fever Research Institute, Entebbe, Uganda. That this virus can also infect man was clear when Dick himself contracted the infection, whether naturally or through laboratory exposure is not known. He suffered from fever, associated with intense headache, nerve deafness and weakness of the trapezius.

It thus appears that a new group of viruses has been uncovered. As one member of this group, the Mengo virus, was isolated in Uganda; as the two others, the MM and the encephalomyocarditis virus, were isolated in the United States; and as it has been shown that the sera of some soldiers who suffered an acute illness in the Pacific theatre of war neutralize the virus of encephalomyocarditis, it appears that this group of viruses has a wide distribution in the world. How often they cause disease in man, and whether this disease in man often simulates poliomyelitis, has not yet been determined.

\section{Spread of Infection}

The method of spread of the virus of poliomyelitis remains a vexed question. In considering this problem it is relevant to note where the virus is found during an epidemic. It obviously is present in the patient, from whom it can be readily isolated from the throat for 4-5 days prior to the onset of symptoms, and for 3-4 days afterwards. Apart from this limited period, the virus has only rarely been detected in the throat. On the other hand, it can be readily isolated from the faeces of a larger proportion of cases and for a longer time, regularly for three weeks and occasionally for even as long as 12 weeks (Horstmann et al., 1944).

The virus has occasionally been isolated from the throats (Howe and Bodian 1947) and has repeatedly been isolated from the faeces of apparently healthy contacts of cases. It can be regularly isolated from the group in intimate association with the patient, such as the family contacts. This group may remain infected for as long as two months after the occurrence of the first, and maybe the only, paralytic case. The high incidence of infection among household contacts has been emphasized by a number of investigators, in contrast to the relatively lower incidence among -extra-household contacts and the still lower incidence among non-contacts in the same neighbourhood. This indicates that there is no widespread infection in the neighbourhood caused by some factor in the environment common to all. It suggests that a source of infection exists in the household. It seems most probable that this source of infection is one of the infected members of the household. This suggests that infection takes place by contact. Infection of contacts may take place from virus in the secretion of the throat and from virus excreted in the faeces. That the virus from the throat may be responsible for contact transmission is seen in the agreement between the infectious period of a case as determined by epidemiological study and the period during which the virus may be recovered from the throat (Gordon, et al., 1948).

Observations of Aycock and Kessell (r943) indicated an infectious period extending from four days before to five days after onset of symptoms. If faecal virus were responsible for transmission during contact, the period of infectiousness of a case would begin earlier and last longer than has been found to be the case. 
However, the acceptance of the respiratory droplet transmission hypothesis leaves unexplained the remarkable seasonal incidence of poliomyelitis. Although winter epidemics have been described, epidemics in temperate climates occur almost without exception in the summer and autumn months of the year, the time when known alimentary infective diseases such as typhoid and dysentery are commonest, and the time of year when insects and other arthropods are prevalent. It is relevant then to question where else, besides patients and contacts, may the virus be found.

The virus has been isolated from the sewage of cities and towns during an epidemic. In a sewage works, the virus was found in the settled sewage and the humus tank effluent, but not in the sandfiltered effluent (Gear, I946). Virus has not yet been found in the sewage in inter-epidemic years, which include non-epidemic summer months. As its presence in sewage reflects the degree of infection of a community, it follows that infection of the community is widespread during an epidemic. It also indicates that in the winter and in non-epidemic summers, virus is not present in sufficient amount to be demonstrable by the inoculation of small amounts of sewage into monkeys. This does not mean there may not be a few infections in the community. It does exclude widespread infection.

As the virus has been demonstrated in the humus tank effluent, it is possible that water supplies may become contaminated from this source. However, there was no evidence in the recent epidemics to suggest that infection was commonly waterborne. There are only a few authentic examples of milkborne cases. The vast majority of cases are obviously not infected from milk.

The summer incidence naturally raises the question as to whether poliomyelitis may not be an arthropod-borne disease. The virus has been isolated from flies on a number of occasions, since Paul and Trask first demonstrated its presence in flies in 1940. There is still controversy as to whether the presence of virus in flies is of major importance in the epidemiology of the disease, or whether it is an incidental finding when the virus is prevalent in the community. Some argue that as the virus is present in the faeces and in the sewage during an epidemic, it is not surprising that virus is found in batches of flies, but these authorities, mostly epidemiologists, deny that flies play a major role in the spread of poliomyelitis (Anderson, 1947). However, the suspicion that flies may have some role in the spread of poliomyelitis is strengthened by recent observations by Melnick and Penner (1947).
They observed that after feeding infected human stools to the blowfly Phormia regina, virus could be detected in their excreta for 2-3 weeks. In contrast, biologically inert carmine and Theiler's virus were detected in gradually decreasing quantities for 3-5 days only. It has not yet been proved that the virus multiplies in the fly, but these findings certainly suggest that there may be a biological relationship between flies and the virus. Their further reports should be awaited with interest.

The seasonal incidence of poliomyelitis and the deciduous fruit season correspond in almost all countries of the world, but as yet no direct relationship between eating fruit and infection with the virus has been demonstrated.

To summarize then, it appears that the only clear evidence is of spread from human to human. There are so many clear instances that there is general agreement that this is a common method of spread. It is not clear whether the spread takes place via respiratory droplets or via hand to mouth contamination. From the public health point of view, perhaps, it is not important as long as it is recognized that infection takes place from human to human. There is also general agreement that this may not be the only method of spread. Indeed, it seems probable that poliomyelitis may be spread both as a respiratory droplet infection and as an alimentary infective disease.

\section{Laboratory Infections}

Virus diseases are notorious for causing laboratory infections. Poliomyelitis was once regarded as an exception, but this is no longer the case. A number of cases in which the infection was probably acquired in the laboratory are on record (Sabin and Ward, I94I ; Gear, I946 ; Wenner and Paul, 1947). All laboratory technicians concerned were working with strains recently isolated from human -sources. Two cases ended fatally. It should be stressed that such work is not without danger. Cases amongst nurses and doctors attending cases, although not numerous, are not as infrequent as commonly supposed.

Natural laboratory infections of primates are also on record. Howe and Bodian (1944) described a case of natural infection of a chimpanzee. Recently Bodian (1948) has described a natural infection of a rhesus monkey fed on desoxypyridoxine.

\section{Pathogenesis}

However poliomyelitis is spread, there is no doubt that of those infected only a minority develop symptoms and still fewer develop paralysis. Various estimates have been made as to the pro- 
portion of silent and recognizable infections. Laboratory studies suggest that for every io persons infected only one will have symptoms. The immunity surveys in which it has been shown that $80-100$ per cent. of adults are immune to the Lansing strain suggest that the proportion of silent infections must be much higher and may be of the order of 1,000 to $I$.

The question as to why the unlucky few develop paralysis is obviously a very important one. It has long been suspected that undue fatigue and violent exercise predispose a person to a paralytic attack. Ritchie Russell (1947) recently investigated the role of exercise in his series of cases and found that all the severely paralysed cases had undergone severe exertion within a probably significant period before the onset of his illness.

The role of tonsillectomy is still in dispute. Although the chances of being infected when the operation is performed are slight, if a person or child should be harbouring the virus at the time of operation or should become infected soon afterwards, there seems to be no doubt that he is much more liable to a bulbar form of the disease than a person who has not recently undergone the operation of tonsillectomy. Carious teeth and breaches of the mucous membrane are suspected portals of entry of the virus, but no conclusive incrimination of their role has been forthcoming. Nevertheless, they should continue to be suspect. In times of epidemic therefore it is wise to avoid operations on the oro-nasal mucous membrane and to avoid excessive or exhausting exercise.

There is little evidence to suggest that bacterial infections of the intestine play any part in increasing liability to the paralytic form of the disease.

How poliomyelitis invades the central nervous system is a question of considerable practical and theoretical interest. It is now clear that it does not invade the central nervous system via the olfactory nerves and bulb. This route is commonly taken in monkeys infected by intranasal instillation of the virus. These monkeys show lesions of the olfactory bulb, but such lesions are rarely found in naturally occurring fatal human cases.

Titrations of different tissues of such fatal human cases have shown that in addition to the central nervous system, the virus is present in the pharyngeal mucosa, in the jejunal wall, and in the faecal contents but not the wall of the large intestine. On occasion the virus has been isolated from the mesenteric lymph glands, and in one fatal laboratory infection following contamination of a cut hand, in the corresponding axillary lymph glands. Careful studies of the pathology in fatal human cases and in experimental animals indicate that the virus gains entrance to the central nervous system via the axones of nerves. The nerves supplying the throat are especially implicated. ڤ Recent work by Faber et al. (1948) on monkeys has indicated that virus is much more likely to $\stackrel{\mathbb{Q}}{\complement}$ infect the central nervous system following an $\subset$ infection of the throat than one of the small $\underset{\vec{s}}{\vec{s}}$ intestine.

\section{Pathology}

Recent work by Bodian (1948) has shown that $\frac{\bar{D}}{\bar{D}}$ only certain parts of the central nervous system $\unrhd$ are affected by the pathological lesions of poliomyelitis. These include the anterior horn cells of $\overrightarrow{0}$ the spinal cord and brain stem, the thalamus and $\overrightarrow{-}$ the motor area of the brain: The other areas of $\vec{\omega}$ the brain, brain stem and, thalamus are spared. $\frac{\sigma}{D}$ This complete picture is often of value in deciding whether a case is polıomyelitis or not.

Regarding the cytopathology, he notes that the of changes occurring in the basophilic Nissl sub- ${ }^{\prime}$ stance of the cytoplasm appear to be valid in- $\omega$ dicators of the functional state of the neurone.

\section{Immunity}

The immunity following an attack of poliomyelitis appears to be of long duration. It is not yet known whether repeated subclinical infections are necessary to maintain the state of immunitg $\vec{\varphi}$ Considering the age distribution of cases, the $\frac{10}{6}$ seems unlikely. Although not unknown, seconf attacks of paralytic poliomyelitis are rare.

Intensive efforts are naturally being made to develop a prophylactic vaccine. A relatively avirulent strain of the Lansing virus has been developed (Theiler, I948), but for obvious reasons this has not been given a human trial. Experimentally, vaccines containing inactive virus have been made which have conferred protection on the monkeys inoculated, so that they resist infection when challenged with a fully virulent strain. Methods of producing these killed vaccines on a large scale have not yet been evolved.

\section{Prevention of Spread}

The general precautions usually adopted for dealing with an epidemic of poliomyelitis include the isolation of cases, the closing of schools and swimming baths, and the prohibition of children from attending public gatherings and places of $\sigma$ entertainment. To be effective, the isolation $N$ would have to include the whole of each affected $\underset{\omega}{\mathcal{N}}$ family and the period should be extended from 0 three to eight weeks. Such stringent isolation is usually impracticable, for other reasons un- $\frac{\mathscr{C}}{\mathbb{D}}$ desirable and often unavailing.

Indeed, experience has shown that all the measures enforced to prevent the spread of poliomyelitis have little effect. It could hardly be $\stackrel{\mathbb{D}}{\stackrel{\circ}{ }}$ otherwise in a disease in which only a small 
proportion of those infected show symptoms of infection and are recognized. To quote Molner (1948). 'The only significant statement which a' person can make as far as prophylaxis of poliomyelitis is concerned is that up to this time nothing has been found to be effective, and the only encouraging statement which can be made is that clinical and research efforts are ever expanding in the hope of finding some effective ways and means through which preventive measures may be exercised.'

\section{BIBLIOGRAPHY}

ANDERSON, G. W. (1947), Lancet, 67, 10-13.

AYCOCK, W. L. (1948), Personal communication.

AYCOCK, W. L., and KESSEL, J. F. (1943), Am. F. med. Sci., 205, 454-465.

BIETER, R. N. (1948), 'Experimental Chemotherapy of Poliomyelitis; Proceedings First International Poliomyelitis Conference.

BODIAN, D. (1948), Am. F. Hyg., 48, 87.

BODIAN, D. (1948), Bull. Fohns Hopkins Hospital, 83, I.

BURNET, F. M., and KEOGH, E. V. (1938), Med. f. Australia, 2, 130.

DICK, G. W. A., BEST, A. M., HADDOW, A. J., and SMITHBURN, K. C. (1948), Lancet, 2, 286-289.

ENRIGHT, J. B., and SCHULTZ, E. W. (1947), Proc. Soc. exp. Biol. and Med., 66, 54I-544.

FABER, H. K., SILVERBERG, R., DONG, L., and LUZ, L. (1948), ' Entry and Excretion of Poliomyelitis Virus,' Proceedings First International Poliomyelitis Conference.
GARD, S., and LINDHOLM, O. (1947), Acta med. Scandinav., 129, 184-192.

GEAR, J. H. S. (1946), 'Poliomyelitis in Southern Africa'' Proc. Congress S. Afr. med. Ass.

GOLLAN, F. (1948), 'Purification of the MM Poliomyelitis Virus,' Proceedings First International Poliomyelitis Conference.

GORDON, F. B., SCHABEL, F. M., CASEY, A. E., and FISHBEIN, W. L. (1948), f. infect. Dis., 82, 294.

HORSTMAN, D. M., WARD, R., and MELNICK, J. L. (1944), F. Amer. med. Ass., 126, 1061.

HOWE, H. A., and BODIAN, D. (1947), Amer. F. Hyg., 45, 219.

HOWE, H. A., and BODIAN, D. (1944), f. exp. Med., 80, 383.

LEAKE, J. P., BOLTEN, J., and SMITH, H. F. (1917), Publ. Health Rep. Wash., 32, 1995-2015.

MCALPINE, D. (1945), Lancet, 2, 130.

MELNICK, J. L., and PENNER, L. R. (1947), Proc. Soc. exp. Biol. and Med., 65, 342-346.

MORGAN, I. (1948), 'Mechanisms of Immunity in Poliomyelitis, Proceedings First International Poliomyelitis Conference.

MOLNER, J. G. (1948), New Orleans Med. and .Surg. F., 100, 408-413.

PAUL, J. R., HAVEiNS, W. P., and VAN ROOYEN, C. C. (1944), 'Poliomyelitis in British and American Troops in the Middle East.'

PAUL, J. R. (1947), Amer. F. Hyg., 45, 206.

RINEHART, J. F. (944), f. ment. and nerv. Dis., 99, 822.

RUSSELL, R. (194i), Brit. med. f., 2, 1023.

SABIN, A. B., and 'I'ARD, R. (194I), Science, 94, II3.

SEDDON, H. J. (!.:43), Lancet, 2, 549.

THEILER, M. (1!148), Personal communication.

WARD, R., and SA.IIIN, A. B. (1944), Yale J. Biol. and Med., 16, 45I.

WARREN, J., Pers:nal communication.

WENNER, H. A., al I PAUL, J. R. (1947), Amer. F. med. Sci., 213, 9-18.

\section{EDITORIAL-(Continued from page 2)}

writing in the closing years of last century, described the epidemic nature of the disease. Such was the influence of these two that it became known as the Heine-Medin disease.

In rgog Landsteiner and Popper successfülly transferred the disease to rhesus monkeys by intraperitoneal injection from a fatal human case. Intracerebral injection was soon found to be equally effective, whilst filtration through the finest porcelain filter failed to prevent the passage of the causative agent. In I913 Flexner and Noguchi described the globoid bodies which were only shown to be incidental in the disease after much study in 1936. Rosenow persisted in his streptococcal theory. Experimental work was greatly handicapped by the necessity for using monkeys. Much enthusiasm was therefore shown when Armstrong in 1939 succeeded in transferring the Lansing strain of the virus to the cotton rat and thence to white mice. This and a number of other strains have been isolated from cases occurring in different parts of the world and have been shown to have different characteristics.
More recently the virus has been obtained in fairly pure form by ultra-centrifugation. It has been cultured with difficulty, the greatest success being obtained on media containing living nervous tissues using tissue culture methods, emphasizing the neurotropic property of the virus. By electron microscopy it has been shown to be filamentous in nature and to have a particle size from $10-25 \mu$. It is thought to contain nucleoprotein but its chemical analysis is still far from complete.

The need for research into the cause and method of spread of this scourge has been recognized in the United States in the National Foundation for Infantile Paralysis (see page 18). Inspired by the dynamic personality of President Roosevelt and generously supported by public subscription, this foundation has instigated and financed an enormous amount. of research in all branches of the subject. Not least of its benefactions is the publication of a monthly summary of world literature on the subject. We pray that the labours of these and other workers will be rewarded. 